\title{
PERTUMBUHAN DAN HASIL TANAMAN GANDUM (Triticum aestivum L.) VARIETAS DEWATA DALAM POLYBAG PADA BERBAGAI POPULASI DAN KOMPOSISI MEDIA TANAM
}

\section{THE GROWTH AND YIELD OF DEWATA WHEAT VARIETIES PLANTED POLYBAG AT VARIOUS POPULATION DENSITIES AND MEDIA COMPOSITIONS}

\author{
Nugraheni Widyawati \\ Fakultas Pertanian \& Bisnis Universitas Kristen Satya Wacana \\ heniwidya@gmail.com
}

Diterima 14 Juni 2013, disetujui 12 November 2013

\begin{abstract}
Studies on the growth and yield performance of wheat (Triticum aestivum L. variety of Dewata) planted in polybag with various populations and media compositions, had been conducted in Faculty of Agriculture Satya Wacana Christian University field research, located at Salaran Kopeng village, Semarang district, from April 2012 to August 2012. Location of the study lies at an altitude of 900 meters above the sea level. Purpose of this study were to determine the appearance of both the growth and yield of wheat grown in polybag with a various population densities and media composition, as well as to determine the combination of treatments that producing the highest yield of wheat. Factorial design used that was consisted of two factors, i.e: (1) growing gedia composition with four different volume ratio of sand, soil and manure (1:1:1), (1:1:0), (1:0:1) and (0:1:1), and (2) population densities consisted of four: 1 seeds per polybag; 2 seeds per polybag; 3 seeds per polybag and 4 seeds per polybag, so that there were 16 combinations of treatments. Each combination was repeated three times. Basic design of the experiments used Randomized Block Design. Experimental data were analyzed by using analysis of variance (ANOVA) and high significant difference (HSD) test at $95 \%$ level of confidence. The conclusion of this study were: (1) Combination of treatment of population densities and composition of growing media influence on plant height, number of plants per cluster, panicle length, seed weight per panicle, seed weight per cluster and seed weight per polybag and (2) the highest seed weight per polybag was resulted in the density of population of 4 seeds per polybag and planting on mixed media of sand, soil and manure in the volume ratio of 1:1:1.
\end{abstract}

Keywords: wheat, population, media composition, polybag

\section{PENDAHULUAN}

Dalam kegiatan produksi tanaman, keadaan tanah sering menjadi faktor pembatas misalnya karena kadar garam terlalu tinggi, terlalu asam, tanahnya berpasir atau berlempung, tanah tercemar oleh limbah, tanahnya padas, tanahnya sudah berpaving, tanahnya berbatu dls, sehingga kurang sesuai untuk membudidayakan tanaman, termasuk untuk penanaman gandum. Sementara di tempat tersebut sangat diperlukan adanya penanaman untuk tujuan tertentu, misalnya untuk tujuan koleksi, penyimpanan sumber gen, penelitian, pendidikan, pelatihan atau bahkan untuk memperbanyak benih. Kondisi tanah seperti itu, mungkin bisa dimodifikasi atau direkayasa, namun membutuhkan tambahan biaya, waktu dan tenaga, yang seringkali tidak sedikit, sehingga perlu dicari solusi yang mudah dan relatif murah. 
Salah satu cara praktis agar tetap bisa dilakukan penanaman pada lahan atau tanah bermasalah seperti tersebut di atas, adalah penanaman tanaman gandum dalam wadah-wadah atau sering disebut pot. Melalui penanaman dalam wadah atau pot dapat meminimalkan efeknegatif akibat ketidakcocokan yang ditimbulkan oleh sifat fisik atau kimia tanah di lokasi tersebut. Beberapa hal yang harus dipertimbangkan dalam penanaman gandum dalam pot antara lain adalah masalah komposisi media tanam dan kepadatan populasi setiap pot.

Media tanam dalam pot merupakan pengganti tanah, berfungsi tidak hanya sebagai tempat berdirinya tanaman gandum, melainkan juga sebagai penyedia oksigen, air, unsur hara dan energi panas yang diperlukan dalam proses metabolisme tanaman. Kemampuan media tanam dalam menyediakan kondisi yang ideal bagi tanaman sangat tergantung pada komposisi media yang digunakan.

Media tanam yang didominasi oleh partikel pasir mempunyai kapasitas yang rendah dalam menyimpan air dan unsur hara serta rentan terhadap erosi (Djajadi dkk., 2010). Tanah pasir adalah tanah yang bersifat kurang baik bagi pertanian karena memiliki butiran kasar. Pathan dkk, (2002) menyebutkan bahwa tanah berpasir rentan terhadap erosi dan kehilangan unsur hara. Tanah yang didominasi oleh partikel liat mengandung agregat yang lebih banyak, karena partikel liat bermuatan elektrik yang memungkinkan terjadinya prose agregasi tanah (Shepherd dkk., 2002). Tanah kebun pada umumnya mengandung campuran yang kompleks termasuk mengandung partikel liat. Partikel liat dan bahan organik merupakan dua unsur penting dalam proses agregasi dan stabilitas agregat tanah. Penambahan partikel liat sebanyak 5 persen dan 0,8 persen bahan organik pada tanah berpasir dari Australia Barat (89 persen pasir, 3 persen debu dan 8 persen liat) telah meningkatkan stabilitas agregat tanah, biomasa mikrobia, respirasi tanah, dan perakaran tanaman (Djajadi, 2006). Penanaman tanaman gandum menggunakan polybag atau metode pot, diharapkan dapat meminimalkan erosi.

Volume media tanam dalam polybag sangat terbatas, sehingga hanya bisa mendukung populasi tertentu, sementara tanaman gandum memiliki sifat bisa menghasilkan anakan, sehingga membentuk suatu rumpun. Semakin padat populasi tanaman dalam polybag maka kompetisi yang terjadi dalam perolehan sumber daya lingkungan akan semakin tinggi dan bisa berakibat pada rendahnya pertumbuhan dan hasil tanaman. Sementara jika populasinya sangat rendah maka penggunaan tempat dan sumber daya lingkungan yang tersedia menjadi kurang efisien. Mulyaningsih dkk. (2008) menyebutkan bahwa kompetisi adalah salah satu bentuk hubungan antar dua individu atau lebih yang mempunyai pengaruh negatif bagi kedua pihak. Kompetisi interspesifik yang terjadi dalam komunitas tanaman alami sangat tergantung pada ketersediaan unsur hara yang diperlukan tanaman (Rien, 1999).

Hasil penelitian Joedojono (1995) pada tanaman jahe dalam pot menunjukkan bahwa pertumbuhan dan hasil tanaman tidak dipengaruhi oleh waktu tanam tetapi dipengaruhi oleh populasi tanaman. Memperbesar populasi dari 1 tanaman per pot (setara 33300 tanaman per ha.) menjadi 3 tanaman per pot (setara 99900 tanaman per ha.) menurunkan hasil tanaman sebesar 27.56 persen, namun tidak mempengaruhi pertumbuhan rimpang.

Mengingat bahwa belum banyak informasi tentang kombinasi antara komposisi media tanam dan populasi yang tepat untuk membudidayakan tanaman gandum dalam polybag, maka masih diperlukan penelitian tentang hal ini. Tujuan penelitian ini adalah untuk:

1. Mengetahui penampilan pertumbuhan dan hasil tanaman gandum yang ditanam dalam polybag dengan berbagai populasi dan komposisi media tanam.

2. Menentukan populasi benih per polybag dan komposisi media tanam dalam polybag yang 
dapat memberikan hasil tanaman gandum tertinggi.

\section{BAHAN DAN METODE PENELITIAN}

Bahan yang digunakan dalam penelitian ini adalah benih gandum varietas Dewata, polybag sebagai pot tanaman berukuran $(25 \times 40) \mathrm{cm}^{2}$, pasir, tanah, pupuk kandang sapi dan pupuk NPK.

Penelitian dilakukan melalui suatu percobaan lapangan menggunakan Rancangan Dasar Rancangan Acak Kelompok dan Rancangan Perlakuan Faktorial terdiri atas dua faktor yaitu: Komposisi Media dan Populasi Benih per polybag. Komposisi media tanam terdiri atas 4 variasi yaitu K1 = Pasir: Tanah : Pupuk Kandang (1:1:1); K2 = Pasir $:$ Tanah $:$ Pupuk kandang (1:1:0); K3 = Pasir: Tanah : Pupuk kandang (1:0:1); K4 = Pasir : Tanah: Pupuk kandang (0:1:1). Populasi benih gandum per polybag terdiri atas 4 variasi yaitu: $\mathrm{P} 1=1$ benih per polybag; $\mathrm{P} 2=2$ benih per polybag; $\mathrm{P} 3=3$ benih per polybag; $\mathrm{P} 4=4$ benih per polybag. Total perlakuan terdiri atas 16 kombinasi yaitu: K1P1; K1P2; K1P3; K1P4; $\mathrm{K} 2 \mathrm{P} 1 ; \mathrm{K} 2 \mathrm{P} 2$; K2P3; K2P4; K3P1; K3P2; K3P3; K3P4; K4P1; K4P2; K4P3;K4P4. Masingmasing kombinasi perlakuan diulang sebanyak 3 kali.

\section{HASIL DAN PEMBAHASAN}

A. Kandungan Hara Berbagai Komposisi Media Tanam

Dari hasil analisis kandungan hara, pada Tabel 1 terlihat bahwa pasir, tanah dan pupuk kandang yang digunakan sebagai media campuran ternyata bersifat masam,

Tabel 1. Hasil analisis kandungan N,P,K, bahan organik dan $\mathrm{pH}$ dari berbagai komposisi media tanam

\begin{tabular}{lcccccccccc}
\hline $\begin{array}{c}\text { Pasir:Tanah: } \\
\text { Pupuk } \\
\text { kandang }\end{array}$ & \multicolumn{2}{c}{ N total } & \multicolumn{2}{c}{ P tersedia } & \multicolumn{2}{c}{ K tersedia } & \multicolumn{2}{c}{ Bhn Organik } & \multicolumn{2}{c}{ pH H2O } \\
\cline { 2 - 10 } & $\%$ & Harkat & ppm & Harkat & ppm & Harkat & $\%$ & Harkat & Nilai & Harkat \\
\hline 1:1:1(1) & 0,23 & S & 61,93 & ST & 465,18 & ST & 3,01 & S & 5,37 & Msm \\
$1: 1: 1(2)$ & 0,28 & S & 59,64 & ST & 454,44 & ST & 3,61 & S & 5,34 & Msm \\
$1: 1: 1(3)$ & 0,2 & S & 58,30 & ST & 484,59 & ST & 3,12 & S & 5,34 & Msm \\
$1: 1: 0(1)$ & 0,10 & SR & 13,15 & T & 33,12 & SR & 1,79 & R & 5,33 & Msm \\
$1: 1: 0(2)$ & 0,09 & SR & 14,53 & T & 32,82 & SR & 1,28 & R & 5,32 & Msm \\
$1: 1: 0(3)$ & 0,09 & SR & 15,07 & T & 32,59 & SR & 1,21 & R & 5,31 & Msm \\
$1: 0: 1(1)$ & 0,69 & T & 72,21 & ST & $1.341,57$ & ST & 6,60 & ST & 5,30 & Msm \\
$1: 0: 1(2)$ & 0,70 & T & 65,61 & ST & $1.334,31$ & ST & 6,74 & ST & 5,29 & Msm \\
$1: 0: 1(3)$ & 0,69 & T & 71,03 & ST & $1.323,23$ & ST & 6,65 & ST & 5,28 & Msm \\
$0: 1: 1(1)$ & 0,24 & S & 53,66 & ST & 590,36 & ST & 3,29 & S & 5,27 & Msm \\
$0: 1: 1(2)$ & 0,22 & S & 52,13 & ST & 633,10 & ST & 2,99 & S & 5,26 & Msm \\
$0: 1: 1(3)$ & 0,25 & S & 53,50 & ST & 607,06 & ST & 3,19 & S & 5,26 & Msm \\
\hline Pasir & 0,09 & SR & 11,07 & S & 22,01 & SR & 0,45 & SR & 5,26 & Msm \\
Pupuk Kandang & 1,54 & ST & 69,90 & ST & $4.738,72$ & ST & 6,95 & ST & 5,25 & Msm \\
Tanah & 0,18 & R & 39,95 & ST & 42,00 & R & 2,84 & S & 5,25 & Msm \\
\hline
\end{tabular}

Keterangan: R: rendah; S: sedang; T; tinggi; ST: sangat tinggi; Msm: masam. 
sehingga percampurannyapun menjadi masam pula.Tanaman gandum tumbuh optimal pada $\mathrm{pH}$ tanah 6,5-7,1. Dari hasil analisis ini bisa dikatakan bahwa keasaman media yang digunakan dalam penelitian ini relatif rendah. Media tanam yang bersifat masam dapat menyebabkan kelarutan unsur hara menjadi rendah sehingga mengurangi penyerapan hara oleh tanaman.

Kandungan N,P K dan bahan organik dari pupuk kandang yang digunakan termasuk sangat tinggi. Hal ini menyebabkan kandungan hara pada media yang mengandung pupuk kandang ini menjadi relatif tinggi, sementara kombinasi media yang tidak mengandung pupuk kandang menyebabkan kandungan $\mathrm{N}, \mathrm{K}$ dan bahan organiknya termasuk rendah hingga sangat rendah.

\section{B. Penampilan Pertumbuhan Tanaman Gandum}

Dua parameter yang disajikan di bawah ini untuk memberikan gambaran tentang pertumbuhan vegetatif tanaman gandum, yaitu tinggi tanaman dan jumlah tanaman per rumpun.
Dari hasil analisis terhadap rata-rata tinggi tanaman gandum (Tabel 2), terlihat bahwa jika media tanamnya tidak menggunakan pupuk kandang, maka hasilnya lebih rendah dibandingkan yang menggunakan campuran lengkap (pasir + tanah + pupuk kandang $=1: 1: 1$ ). Hasil analisis ini menunjukkan bahwa pemberian pupuk kandang sangat penting terutama pada populasi benih per polybag dengan kepadatan tinggi.

Hasil analisis terhadap jumlah tanaman per rumpun (Tabel 3) menunjukkan bahwa jumlah tanaman/ rumpun paling banyak terdapat pada populasi 1 benih per polybag dengan menggunakan media tanam lengkap yaitu campuran pasir+tanah + pupuk kandang (1:1:1). Media tanam tanpa menggunakan pupuk kandang ternyata menyebabkan jumlah tanaman per rumpun relatif sedikit. Hasil analisis ini juga menunjukkan bahwa pemberian pupuk kandang dalam media tanam sangat penting untuk memacu pertumbuhan anakan dalam satu rumpun.

Tabel 2. Tinggi tanaman gandum $(\mathrm{cm})$ pada berbagai kepadatan populasi dan komposisi media tanam

\begin{tabular}{cccccc}
\hline & $\begin{array}{c}\text { 1 Benih } \\
\text { per polybag }\end{array}$ & $\begin{array}{c}\text { 2 Benih } \\
\text { per polybag }\end{array}$ & $\begin{array}{c}\text { 3 Benih } \\
\text { per polybag }\end{array}$ & $\begin{array}{c}\text { 4 Benih } \\
\text { per polybag }\end{array}$ & $\begin{array}{c}\text { Efek } \\
\text { utama }\end{array}$ \\
\hline Pasir:Tanah:Pupuk Kandang & 51.63 a & 56.43 a & 57.21 a & $57.72 \mathrm{~b}$ & $c$ \\
1:1:1 & $\mathrm{A}$ & $\mathrm{A}$ & $\mathrm{A}$ & $\mathrm{A}$ & \\
Pasir:Tanah:Pupuk Kandang & $44.71 \mathrm{a}$ & $45.29 \mathrm{a}$ & $46.78 \mathrm{a}$ & $45.11 \mathrm{a}$ & $\mathrm{a}$ \\
1:1:0 & $\mathrm{A}$ & $\mathrm{A}$ & $\mathrm{A}$ & $\mathrm{A}$ & \\
Pasir:Tanah:Pupuk Kandang & $43.96 \mathrm{a}$ & $51.03 \mathrm{a}$ & $48.18 \mathrm{a}$ & $46.45 \mathrm{ab}$ & $a b$ \\
1:0:1 & $\mathrm{A}$ & $\mathrm{A}$ & $\mathrm{A}$ & $\mathrm{A}$ & \\
Pasir:Tanah:Pupuk Kandang & $51.40 \mathrm{a}$ & $53.22 \mathrm{a}$ & $52.35 \mathrm{a}$ & $51.85 \mathrm{ab}$ & $\mathrm{bc}$ \\
0:1:1 & $\mathrm{A}$ & $\mathrm{A}$ & $\mathrm{A}$ & $\mathrm{A}$ & \\
\hline Efek utama & $A$ & $A$ & $A$ & $A$ & \\
\hline
\end{tabular}

Keterangan: Huruf kecil kebawah menunjukkan pengaruh komposisi media tanam pada tiap populasi benih per polybag. Huruf besar ke samping kanan menunjukkan pengaruh populasi benih per polybag pada setiap komposisi media tanam. 
Pertumbuhan vegetatif yang lebih unggul tersebut disebabkan karena ketersediaan unsur hara makro dalam media tanam termasuk sedang hingga sangat tinggi (Tabel 1), sehingga diduga mampu memenuhi kebutuhan untuk mendukung proses pembelahan sel dan pembesaran sel pada jaringan meristematis selama berlangsungnya masa pertumbuhan vegetatif. Ketersediaan unsur hara tersebut menyebabkan kompetisi yang terjadi dalam penggunaan unsur hara dapat diminimalisir, sehingga jumlah anakan yang mampu tumbuh tidak terhambat. Setiap anakan dapat tumbuh dengan baik karena bahan dasar yang diperlukan untuk proses pembentukan berbagai senyawa organik yang diperlukan untuk membesarkan selsel tersedia dalam media tanam serta lingkungannya dalam jumlah optimal.

Tabel 3. Jumlah tanaman per rumpun pada berbagai kepadatan populasi dan komposisi media tanam

\begin{tabular}{cccccc}
\hline & $\begin{array}{c}\text { 1 Benih } \\
\text { per polybag }\end{array}$ & $\begin{array}{c}\text { 2 Benih } \\
\text { per polybag }\end{array}$ & $\begin{array}{c}\text { 3 Benih } \\
\text { per polybag }\end{array}$ & $\begin{array}{c}\text { 4 Benih } \\
\text { per polybag }\end{array}$ & $\begin{array}{c}\text { Efek } \\
\text { Utama }\end{array}$ \\
\hline Pasir:Tanah:Pupuk & $8.06 \mathrm{c}$ & $5.25 \mathrm{~b}$ & $4.67 \mathrm{~b}$ & $4.00 \mathrm{a}$ & $\mathrm{c}$ \\
1:1:1 & $\mathrm{B}$ & $\mathrm{AB}$ & $\mathrm{A}$ & $\mathrm{A}$ & \\
Pasir:Tanah:Pupuk & $1.84 \mathrm{a}$ & $2.07 \mathrm{a}$ & $1.82 \mathrm{a}$ & $2.16 \mathrm{a}$ & $a$ \\
1:1:0 & $\mathrm{A}$ & $\mathrm{A}$ & $\mathrm{A}$ & $\mathrm{A}$ & \\
Pasir:Tanah:Pupuk & $3.37 \mathrm{ab}$ & $2.74 \mathrm{ab}$ & $2.34 \mathrm{ab}$ & $1.85 \mathrm{a}$ & $a b$ \\
1:0:1 & $\mathrm{A}$ & $\mathrm{A}$ & $\mathrm{A}$ & $\mathrm{A}$ & \\
Pasir:Tanah:Pupuk & $4.39 \mathrm{~b}$ & 3.24 ab & 3.27 ab & $3.65 \mathrm{a}$ & $b$ \\
0:1:1 & $\mathrm{A}$ & $\mathrm{A}$ & $\mathrm{A}$ & $\mathrm{A}$ & \\
\hline Efek utama & $\mathrm{B}$ & $\mathrm{A}$ & $A B$ & $A B$ & \\
\hline
\end{tabular}

Keterangan: Huruf kecil ke bawah menunjukkan pengaruh komposisi media tanam pada tiap populasi benih per polybag. Huruf besar ke samping kanan menunjukkan pengaruh populasi benih per polybag pada setiap komposisi media tanam.

\section{Penampilan Hasil Tanaman Gandum}

Tabel 4. Berat biji/malai tanaman gandum pada berbagai kepadatan populasi dan komposisi media tanam $(\mathrm{g})$

\begin{tabular}{cccccc}
\hline & $\begin{array}{c}\text { 1 Benih } \\
\text { per polybag }\end{array}$ & $\begin{array}{c}\text { 2 Benih } \\
\text { per polybag }\end{array}$ & $\begin{array}{c}\text { 3 Benih } \\
\text { per polybag }\end{array}$ & $\begin{array}{c}\text { 4 Benih } \\
\text { per polybag }\end{array}$ & $\begin{array}{c}\text { Efek } \\
\text { Utama }\end{array}$ \\
\hline $\begin{array}{c}\text { Pasir:Tanah:Pupuk } \\
\text { 1:1:1 }\end{array}$ & 0.88 & 0.73 & 0.79 & 0.83 & $a$ \\
$\begin{array}{c}\text { Pasir:Tanah:Pupuk } \\
\text { 1:1:0 }\end{array}$ & 0.39 & 0.48 & 1.37 & 1.30 & $a$ \\
$\begin{array}{c}\text { Pasir:Tanah:Pupuk } \\
\text { 1:0:1 }\end{array}$ & 0.40 & 0.50 & 0.45 & 0.40 & $a$ \\
$\begin{array}{c}\text { Pasir:Tanah:Pupuk } \\
\text { 0:1:1 }\end{array}$ & 0.54 & 0.67 & 0.91 & 0.70 & $a$ \\
\hline Efek utama & $A$ & $A$ & $A$ & $A$ & \\
\hline
\end{tabular}

Keterangan: Huruf kecil ke bawah menunjukkan pengaruh komposisi media tanam pada tiap populasi benih per polybag. Huruf besar ke samping kanan menunjukkan pengaruh populasi benih per polybag pada setiap komposisi media tanam. 
Tabel 5. Berat biji per rumpun (g) tanaman gandum pada berbagai kepadatan populasi dan komposisi media tanam

\begin{tabular}{cccccc}
\hline & $\begin{array}{c}\text { 1 Benih } \\
\text { per polybag }\end{array}$ & $\begin{array}{c}\text { 2 Benih } \\
\text { per polybag }\end{array}$ & $\begin{array}{c}\text { 3 Benih } \\
\text { per polybag }\end{array}$ & $\begin{array}{c}\text { 4 Benih } \\
\text { per polybag }\end{array}$ & $\begin{array}{c}\text { Efek } \\
\text { Utama }\end{array}$ \\
\hline Pasir:Tanah:Pupuk & $5.40 \mathrm{~b}$ & $3.75 \mathrm{a}$ & $3.64 \mathrm{a}$ & $3.37 \mathrm{a}$ & $\mathrm{B}$ \\
1:1:1 & $\mathrm{A}$ & $\mathrm{A}$ & $\mathrm{A}$ & $\mathrm{A}$ & \\
Pasir:Tanah:Pupuk & $0.73 \mathrm{a}$ & $1.06 \mathrm{a}$ & $0.85 \mathrm{a}$ & $2.87 \mathrm{a}$ & $\mathrm{A}$ \\
1:1:0 & $\mathrm{A}$ & $\mathrm{A}$ & $\mathrm{A}$ & $\mathrm{A}$ & \\
Pasir:Tanah:Pupuk & $1.25 \mathrm{a}$ & $1.25 \mathrm{a}$ & $1.00 \mathrm{a}$ & $0.73 \mathrm{a}$ & $\mathrm{A}$ \\
1:0:1 & $\mathrm{A}$ & $\mathrm{A}$ & $\mathrm{A}$ & $\mathrm{A}$ & \\
Pasir:Tanah:Pupuk & $2.41 \mathrm{ab}$ & $2.21 \mathrm{a}$ & $3.87 \mathrm{a}$ & $3.07 \mathrm{a}$ & $A B$ \\
0:1:1 & $\mathrm{A}$ & $\mathrm{A}$ & $\mathrm{A}$ & $\mathrm{A}$ & \\
\hline Efek utama & $\mathrm{A}$ & $\mathrm{A}$ & $\mathrm{A}$ & $A$ & \\
\hline
\end{tabular}

Keterangan: Huruf kecil ke bawah menunjukkan pengaruh komposisi media tanam pada tiap populasi benih per polybag. Huruf besar ke samping kanan menunjukkan pengaruh populasi benih per polybag pada setiap komposisi media tanam.

Tabel 6. Berat biji per polybag tanaman gandum pada berbagai kepadatan populasi dan komposisi media tanam $(\mathrm{g})$

\begin{tabular}{cccccc}
\hline & $\begin{array}{c}\text { 1 Benih } \\
\text { per polybag }\end{array}$ & $\begin{array}{c}\text { 2 Benih } \\
\text { per polybag }\end{array}$ & $\begin{array}{c}\text { 3 Benih } \\
\text { per polybag }\end{array}$ & $\begin{array}{c}\text { 4 Benih } \\
\text { per polybag }\end{array}$ & $\begin{array}{c}\text { Efek } \\
\text { Utama }\end{array}$ \\
\hline Pasir:Tanah:Pupuk & $6.86 \mathrm{~b}$ & $7.52 \mathrm{a}$ & $11.29 \mathrm{~b}$ & $13.81 \mathrm{~b}$ & $\mathrm{~b}$ \\
$1: 1: 1$ & $\mathrm{~A}$ & $\mathrm{~A}$ & $\mathrm{AB}$ & $\mathrm{B}$ & \\
Pasir:Tanah:Pupuk & $0.73 \mathrm{a}$ & $2.16 \mathrm{a}$ & $2.70 \mathrm{a}$ & $4.11 \mathrm{a}$ & $a$ \\
1:1:0 & $\mathrm{A}$ & $\mathrm{A}$ & $\mathrm{A}$ & $\mathrm{A}$ & \\
Pasir:Tanah:Pupuk & $1.25 \mathrm{ab}$ & $2.62 \mathrm{a}$ & $3.30 \mathrm{a}$ & $3.06 \mathrm{a}$ & $a$ \\
1:0:1 & $\mathrm{A}$ & $\mathrm{A}$ & $\mathrm{A}$ & $\mathrm{A}$ & \\
Pasir:Tanah:Pupuk & $2.41 \mathrm{ab}$ & $4.73 \mathrm{a}$ & 7.71 ab & $5.82 \mathrm{a}$ & $a$ \\
0:1:1 & $\mathrm{A}$ & $\mathrm{A}$ & $\mathrm{A}$ & $\mathrm{A}$ & \\
\hline Efek utama & $\mathrm{A}$ & $\mathrm{ABC}$ & $\mathrm{C}$ & $B C$ &
\end{tabular}

Keterangan: Huruf kecil ke bawah menunjukkan pengaruh komposisi media tanam pada tiap populasi benih per polybag. Huruf besar ke samping kanan menunjukkan pengaruh populasi benih per polybag pada setiap komposisi media tanam. 
Dari analisis komponen hasil, menunjukkan bahwa berat biji per malai tidak dipengaruhi oleh komposisi media tanam maupun populasi benih per polybag. Namun pada berat biji per rumpun ternyata komposisi media tanam pasir+tanah+pupuk kandang (1:1:1) lebih tinggi hasilnya dibandingkan jika tanpa pupuk kandang atau tanpa tanah, demikian pula pada berat biji per polybag. Sementara pengaruh populasi baru terlihat pada komponen hasil berat biji per polybag, yaitu semakin banyak populasinya ternyata hasilnya semakin tinggi dan kombinasi yang memberikan hasil tertinggi adalah komposisi media lengkap (1:1:1) dengan populasi 4 benih/polybag.

Dari hasil analisis komponen pertumbuhan dan hasil tanaman tersebut, dapat disimpulkan bahwa pengaruh kepadatan populasi baru nampak jika menggunakan media tanam lengkap yaitu campuran pasir+tanah+pupuk kandang dengan perbandingan 1:1:1. Jika dihubungkan dengan analisis kandungan hara media tanam (Tabel 1), tampak bahwa pupuk kandang yang digunakan mengandung $\mathrm{N}$ total, $\mathrm{P}$ tersedia, $\mathrm{K}$ tersedia dan bahan organik dengan harkat sangat tinggi. Peranan unsur hara makro dalam sintesis berbagai senyawa organik melalui serangkaian proses metabolisme amatlah penting. Senyawa organik hasil metabolism tersebut merupakan bahan dasar dalam proses pembentukan hingga pengisian biji gandum. Kecukupan senyawa organik hasil metabolisme tanaman menyebabkan setiap biji dalam bulir gandum menjadi berisi, sehingga hasil biji per polybag menjadi tinggi. Hasil penelitian Barus (2012) menunjukkan bahwa pemberian pupuk kandang sebanyak 4 ton per ha mampu mening-katkan jumlah anakan, komponen produksi (jumlah malai per rumpun, dan jumlah gabah per malai), dan produksi padi gogo.

Dalam sintesis berbagai senyawa organik melalui proses metabolisme tanaman, diperlukan kecukupan sumberdaya selain unsur hara makro, yaitu energi matahari, CO2, air dan oksigen. Diduga peranan pupuk kandang sebagai campuran media tanam selain menambah unsur hara makro dapat meningkatkan ketersediaan air serta oksigen. Bahan organik tanah merupakan salah satu bahan pembentuk agregat tanah, yang mempunyai peran sebagai bahan perekat antar partikel tanah untuk bersatu menjadi agregat tanah. Bronick dan Lal (2005) menyebutkan bahwa meningkatnya stabilitas agregat pada tanah berpasir dapat memperbaiki kesuburan kimia dan biologis tanah, meningkatkan porositas dan ketahanan tanah terhadap erosi. Suwardjono (2001) menyebutkan bahwa pupuk kandang mempunyai beberapa fungsi antara lain (1) mengembangkan beberapa unsur hara seperti fosfor, nitrogen, sulfur, dan kalium; (2) meningkatkan kapasitas lahan kation tanah; (3) melepaskan unsur P dari oksida Fe dan $\mathrm{Al}$; (4) memperbaiki sifat fisik dan struktur tanah; (5) serta membentuk senyawa kompleks dengan unsur makro dan mikro sehingga dapat mengurangi proses pencucian unsur

Dari hasil penelitian ini ternyata percampuran antara partikel pasir, tanah dan pupuk kandang, menyebabkan media tanam tersebut sangat sesuai untuk mendukung pertumbuhan vegetatif maupun generatif tanaman gandum. Kondisi media tanam seperti itu dalam ukuran pot (polybag) $(25 \times 40)$ $\mathrm{cm}$ ternyata masih mampu mendukung populasi tanaman sebanyak 4 benih per polybag dan memberikan hasil berat biji per polybag tertinggi.

\section{KESIMPULAN}

1. Kombinasi perlakuan kepadatan populasi dan komposisi media tanam berpengaruh terhadap tinggi tanaman, jumlah tanaman per rumpun, panjang malai, jumlah biji per malai, berat biji per malai, jumlah biji per rumpun, berat biji per rumpun dan berat biji per polybag.

2. Kombinasi perlakuan yang memberikan hasil (berat biji per polybag) tertinggi adalah kepadatan polulasi 4 benih per polybag dengan menggunakan media tanam campuran pasir, tanah dan pupuk kandang (1:1:1). 


\section{DAFTAR PUSTAKA}

Barus, J. 2012. Pengaruh Aplikasi Pupuk Kandang dan Sistim Tanam Terhadap Hasil Varietas Unggul Padi Gogo Pada Lahan Kering Masam di Lampung. Jurnal Lahan Suboptimal 1(1): 102-106, April 2012.

Bronick, C.J. and R. Lal. 2005. Soil structure and management: a review. Geoderma 124: 3-22.

Djajadi. 2006. The Roles of Added Clay and Organic Matter in Stabilizing Aggregates in Sandy Soils. PhD Thesis. The University of Western Australia.

Djajadi, B.Heliyanto, N. Hidayah. 2010. Pengaruh Media Tanam dan Frekuensi Pemberian Air terhadap Sifat Fisik, Kimia dan Biologi Tanah serta Pertumbuhan Jarak Pagar. Jurnal Litri 16 (2): 64-69.

Joedojono Wiroatmodjo. 1995. Waktu Tanam dan Populasi Tanaman Jahe (Zingiber officinale Rosc.) sebagai tanaman kedua dalam Pola Tanam Beruntun. Jurnal Agronomi Indonesia (Indonesian Journal of Agronomy), 23(3): 9-13.
Pathan, S.M., L.A.G. Aylmore, and T.D. Colmer. 2002. Reduced leaching of nitrate, ammonium, and phosphorus in a sandy soil by fly ash amendment. Australian Journal of Soil Research. 40:1201-1211.

Rien A. 1999. Interspecific competition in natural plant communities: mechanisms, trade-offs and plant-soil feedbacks. Journal of experimental botany 50: 29-37.

Shepherd, M.A., R. Harrison, and J. Webb, 2002. Managing soil organic matter-implications for soil structure on organic farms. Soil Use and Management 18: 284-292.

Suwardjono. 200. Pengaruh beberapa jenis pupuk kandang terhadap pertumbuhan dan produksi kacang tanah. Jurnal Matematika, Sains dan Teknologi 2 (2). 